\title{
Variations of VLF/LF signals observed on the ground and satellite during a seismic activity in Japan region in May-June 2008
}

\author{
A. Rozhnoi ${ }^{1}$, M. Solovieva ${ }^{1}$, O. Molchanov ${ }^{1}$, P.-F. Biagi ${ }^{2}$, M. Hayakawa ${ }^{3}$, K. Schwingenschuh ${ }^{4}$, M. Boudjada ${ }^{4}$, and \\ M. Parrot ${ }^{5}$ \\ ${ }^{1}$ Institute of the Earth Physics, RAS, 123995, Bolshaya Gruzinskaya 10, Moscow, Russia \\ ${ }^{2}$ Department of Physics, University of Bari, Bari, Italy \\ ${ }^{3}$ Advanced Wireless Communications Research Center, University of Electro-Communications, Chofu, Tokyo, Japan \\ ${ }^{4}$ Space Research Institute, AAS, Graz, Austria \\ ${ }^{5}$ LPC2E/CNRS Orléans, 45071 Orléans cedex 2, France
}

Received: 25 October 2009 - Revised: 28 February 2010 - Accepted: 1 March 2010 - Published: 16 March 2010

\begin{abstract}
Signals of two Japanese transmitters $(22.2 \mathrm{kHz}$ and $40 \mathrm{kHz}$ ) recorded on the ground VLF/LF station in Petropavlovsk-Kamchatsky and on board the DEMETER French satellite have been analyzed during a seismic activity in Japan in May-June 2008. The period of analysis was from 18 April to 27 June. During this time two rather large earthquakes occurred in the north part of Honshu Island 7 May $(M=6.8)$ and 13 June $(M=6.9)$. The ground and satellite data were processed by a method based on the difference between the real signal in nighttime and the model one. For ground observations a clear decrease in both signals has been found several days before the first earthquake. For the second earthquake anomalies were detected only in JJI signal. The epicenters of earthquakes were in reliable reception zone of $40 \mathrm{kHz}$ signal on board the DEMETER. Signal enhancement above the seismic active region and significant signal intensity depletion in the magnetically conjugate area has been found for satellite observation before the first earthquake. Anomalies in satellite data coincide in time with those in the ground-based observation.
\end{abstract}

\section{Introduction}

The effects of seismic activity influence on VLF/LF signals propagation have been found from ground observations (Hayakawa et al., 1996, 2006; Biagi et al., 2004, 2007, 2008; Horie et al., 2007; Maekawa et al., 2006; Rozhnoi et al., 2004, 2005) and from observations on the French DEMETER satellite (Molchanov et al., 2006; Muto et al., 2008, 2009; Solovieva et al., 2009; Boudjada et al., 2008; Slomin-

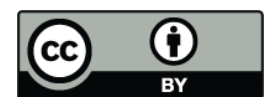

Correspondence to: A. Rozhnoi (rozhnoi@ifz.ru) ska et al., 2009). In our earlier paper (Rozhnoi et al., 2007a) we have presented a correlated analysis of VLF/LF signals radiated by high power transmitters and collected both at ground receivers and on board the satellite. We have shown a reliable decrease of Australian NWC $(19.8 \mathrm{kHz})$ transmitter signal amplitude several days before and after three large earthquakes $(M>6)$ in Japan region from the satellite observation simultaneously with the ground observation signals from two Japanese transmitters $(22.2 \mathrm{kHz}$ and $40 \mathrm{kHz})$. In the analysis we have used the night time data by the alternative electric field receiver ICE (Berthelier et al., 2006) on board the DEMETER satellite in the frequency range $20 \mathrm{~Hz}-$ $20 \mathrm{kHz}$ where the frequency discretization of power spectrum density is $19.53 \mathrm{~Hz}$. This NWC transmitter signal is the most power in the VLF range, so that we could analyze its signal in a large area. In the present paper we use the signal from JJY transmitter $(40 \mathrm{kHz})$ for satellite analysis although this transmitter reception zone is local, but the earthquake epicenters are fortunately located in maximum signal zone. We examine variation of the signal in the region above an earthquake and in its magnetic conjugate region and compare them with the ground based data.

\section{Data processing}

Signals of two Japanese transmitters - JJI $(22.2 \mathrm{kHz})$ and JJY $(40 \mathrm{kHz})$ recorded on the ground VLF/LF station in Petropavlovsk-Kamchatsky and on board the DEMETER French satellites have been analyzed during a seismic activity in Japan in May-June 2008. The period of analysis was from 18 April to 27 June. During this time two rather large independent earthquakes occurred in the north part of Honshu Island (main land of Japan) - 7 May $(M=6.8)$ and 13 June $(M=6.9)$. Information on the earthquakes from

Published by Copernicus Publications on behalf of the European Geosciences Union. 
Table 1. Some characteristics of the large earthquakes and their main foreshocks and aftershocks in analyzed region in the period April-June 2008 (Catalogue USGS).

\begin{tabular}{clllll}
\hline Date & $\begin{array}{l}\text { Time, } \\
\text { UTC }\end{array}$ & Lat & Long & $\begin{array}{l}\text { Depth, } \\
\mathrm{km}\end{array}$ & $M$ \\
\hline 29 April & $05: 26$ & 41.43 & 141.98 & 46 & 5.8 \\
7 May & $16: 02$ & 36.18 & 141.54 & 19 & 6.2 \\
7 May & $16: 16$ & 36.16 & 141.76 & 23 & 6.1 \\
7 May & $16: 45$ & 36.15 & 141.54 & 35 & 6.8 \\
8 May & $23: 21$ & 36.1 & 141.69 & 17 & 5.6 \\
30 May & $07: 25$ & 30.8 & 141.55 & 16 & 5.7 \\
13 June & $23: 43$ & 39.14 & 140.64 & 10 & 6.9 \\
14 June & $00: 20$ & 38.93 & 140.5 & 10 & 5.5 \\
25 June & $23: 37$ & 41.93 & 142.46 & 55 & 5.5 \\
\hline
\end{tabular}

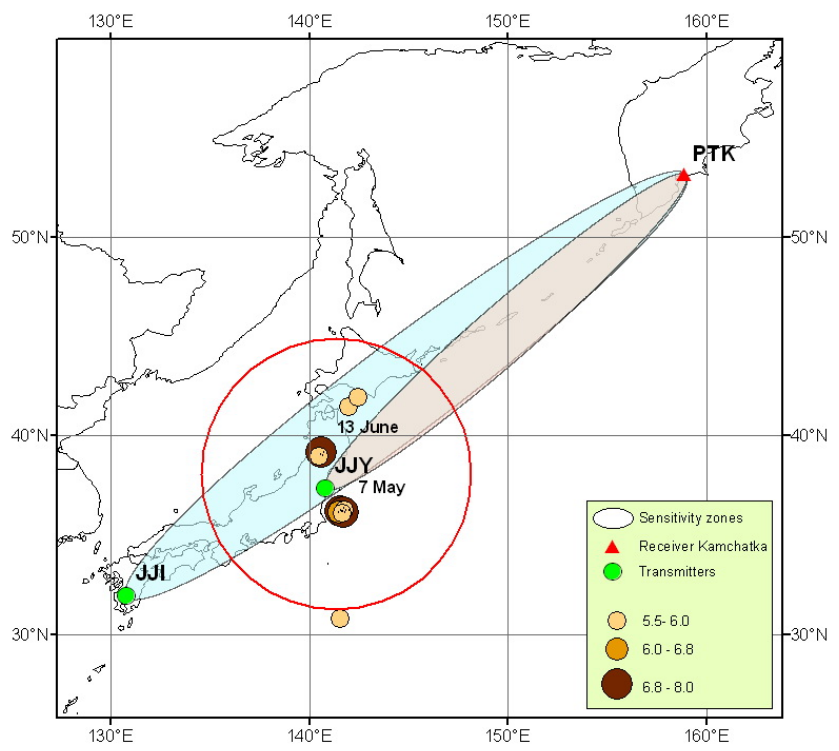

Fig. 1. EQ with $M \geq 5.5$ (including foreshocks and aftershocks) for the period 18 April-30 June 2008. Colored ellipses show sensitivity zones for ground observation of Japanese transmitters: JJY $(40 \mathrm{kHz})$ and JJI $(22.2 \mathrm{kHz})$. Red circle represents the projection on the ground surface of the perturbed zone in the atmosphereionosphere boundary that approximately coincides with a zone of precursory activity.

catalogue USGS (date, time, epicentral location(geographic corrdinate), depth and magnitude) is summarized in Table 1. Strong foreshock activity preceded the 7 May earthquakes. It began on 5 May and two the strongest foreshocks $(M=6.2$ and $M=6.1$ ) occurred shortly before the main shock. After the earthquake there were series of aftershocks with the strongest $(M=5.6)$ on the next day. Earthquake on 13 June occurred suddenly with subsequent aftershock activity. Information about the main foreshocks and aftershocks of these two earthquakes are also given in the table.
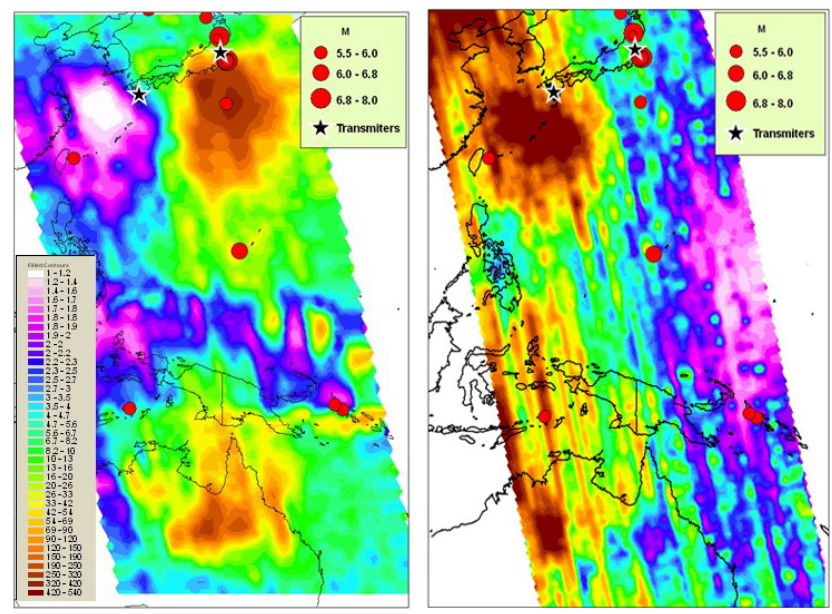

Fig. 2. Night time reception zone of $40 \mathrm{kHz}$ signal (left) and $22.2 \mathrm{kHz}$ signal (right) on the DEMETER satellite.

Relative position of the receiver in PetropavlovskKamchatsky and transmitters with indication of the third Fresnel's zone and epicenters of earthquakes with $M \geq 5.5$ (including foreshocks and aftershocks) for 18 April-30 June is shown in Fig. 1. We suppose that the size of the perturbed zone at the altitude of VLF/LF signal reflection $(\sim 90 \mathrm{~km})$ is about the same of the precursory activity ground zone. This zone is outlined in Fig. 1. Intersection of this zone with the Fresnel's zone is area where the signal can be influenced by the pre-seismic processes.

Data from electric field receiver (ICE) collected on board DEMETER have been used for satellite analysis. Time averaging of the dynamic spectrum is about $2 \mathrm{~s}$, and the space resolution along the orbit is about $10-15 \mathrm{~km}$. Signals of JJI and JJY transmitters are in a high frequency range in which frequency resolution of the spectra is $\Delta F=3.255 \mathrm{kHz}$.

The transmitters are not very powerful, so that reception zones of their signals on board the satellite DEMETER are rather limited as seen in Fig. 2. Epicenters of the earthquakes are inside the reliable reception for $40 \mathrm{kHz}$ signal and outside the reception zone for $22.2 \mathrm{kHz}$ signal. Thus, for satellite analysis only the signal from JJY transmitter has been used. It has been analyzed above the seismic active region and in the magnetically conjugate area. JJY transmitter signal recorded on the satellite DEMETER has been analyzed for the first time by Muto et al. (2008), who have found some drop in signal level above a seismic area during series of Japanese earthquakes.

An example of electric signal at $40 \mathrm{kHz}$ for the part of an orbit above the seismic area (North) and the part of an orbit in magnetic conjugate area (South) is shown in Fig. 3. Zones of analysis in the North and South have a width $25^{\circ}$ that provides one orbit every day. The "cone" of the $40 \mathrm{kHz}$ signal is clearly evident in summary spectra. There are six frequencies here: $29.3,32.55,35.81,42.32,45.57$, and $48.83 \mathrm{kHz}$ with the maximum near $F_{0}=39.06 \mathrm{kHz}$. 

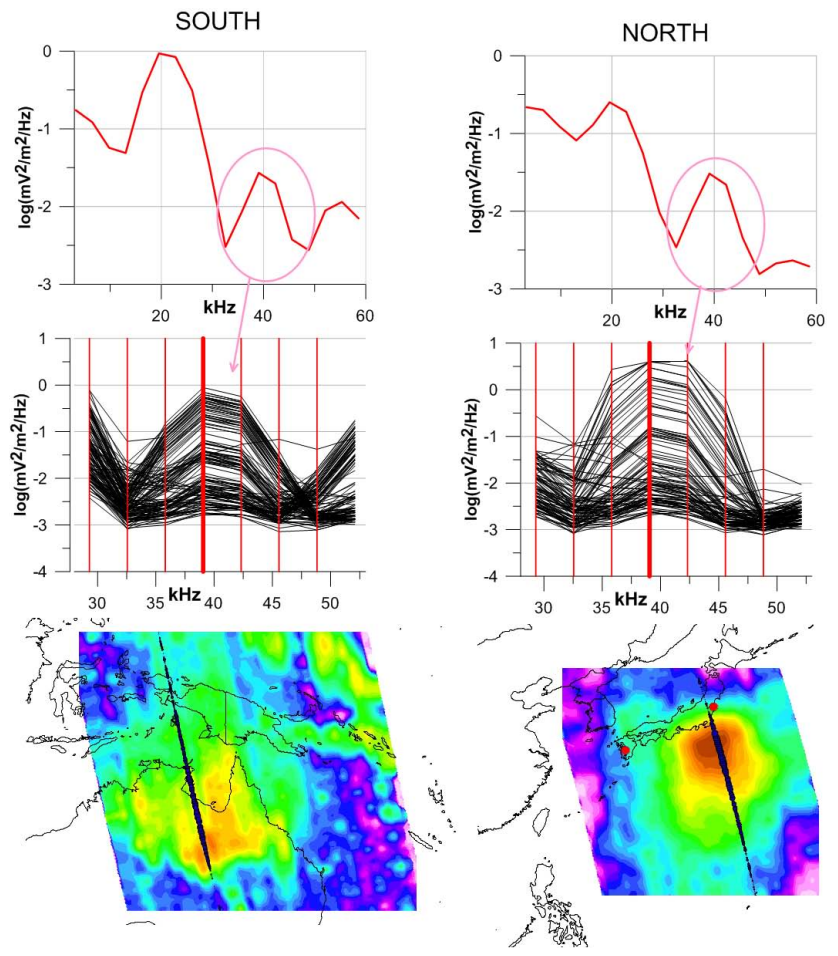

Fig. 3. Example of electric spectra for the part of the orbit above the seismic area (North) and the part of the orbit in magnetic conjugate area (South). The position of the orbits (black line) together with the zones of analysis is shown in the bottom panel. Upper panels present summary spectra in the range $3-60 \mathrm{kHz}$. Central panels present spectra for every point of the orbit part near the signal $40 \mathrm{kHz}$. Thick vertical red line here is $F_{0}=39.06 \mathrm{kHz}$. Thin red lines correspond to the spectral frequencies $F_{i}=29.3,32.55,35.81,42.32$, 45.57 , and $48.83 \mathrm{kHz}$.

The ground and satellite data were processed by a method based on the difference between the real signal in nighttime and the model one (Rozhnoi et al., 2004, 2007). The model for the ground observation was the monthly averaged signal of amplitude or phase calculated for the quiet days of every month.

For satellite observation we calculated the model of a signal for every real orbit based on 2-D model with regular signal distribution over the selected area. The modeling consists of: (a) averaging all the data available in the considered region over the analyzed period, regardless of the global disturbances, in particular, of the magnetic activity; (b) computing a polynomial expression for the surface as a function of longitude and latitude; (c) construction of the regular latitude and longitude grid $0.32^{\circ}$; and (d) computing of a net point model. Models have been calculated for the following characteristics separately for North and South: 1) signal to noise ratio (SNR) defined as a ratio of signal spectrum density near the transmitter frequency $F_{0}=39.06 \mathrm{kHz}$ to the minimum value in frequency band $29.3-48.83 \mathrm{kHz}$ $\left(\mathrm{SNR}=A_{F_{0}} / A_{\min }\right)$; and 2$)$ signal to the averaged value in
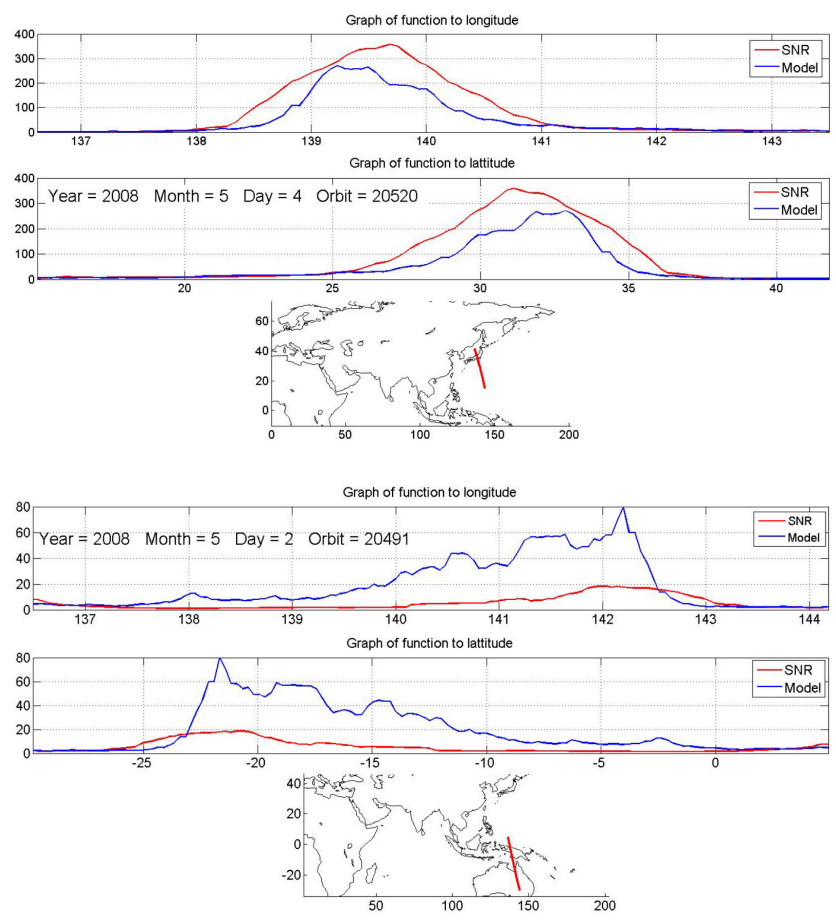

Fig. 4. A comparison of real and model orbits. Upper panel - real and model SNR values for the part of the orbit above earthquakes (North), bottom panel - the same in the magnetic conjugate area (South).

signal broadening band ratio ( $\mathrm{ISB}=A_{0} /<A_{\Delta F}>$ ). The last characteristic is an inverse value of spectrum broadening of the signal (Rozhnoi et al., 2008).

An example of a comparison of SNR real and model data for the North and South regions is shown in Fig. 4. The level of the real signal in South region for the part of the orbit on 2 May represented in the figure is significantly lower than the model signal. For further analysis a deviation of the real data from the model averaged over the night period for ground observation and over the part of an orbit for satellite observation has been used.

\section{Results}

Results of simultaneous ground and satellite observations for the period 18 April-30 June 2008 are shown in Fig. 5. Both in the signal JJI $(22.2 \mathrm{kHz})$ and in the signal JJY $(40 \mathrm{kHz})$ recorded on the ground VLF/LF station in PetropavlovskKamchatsky there is a clear decrease during several days before 7 May earthquake. The decrease of the signals begins 5 days before the earthquake and has the maximal drop 3 days before the earthquake. The effect is more evident for the amplitude and phase of $40 \mathrm{kHz}$ signal. In the phase there is also noticeable effect 5-6 days after the earthquake. 

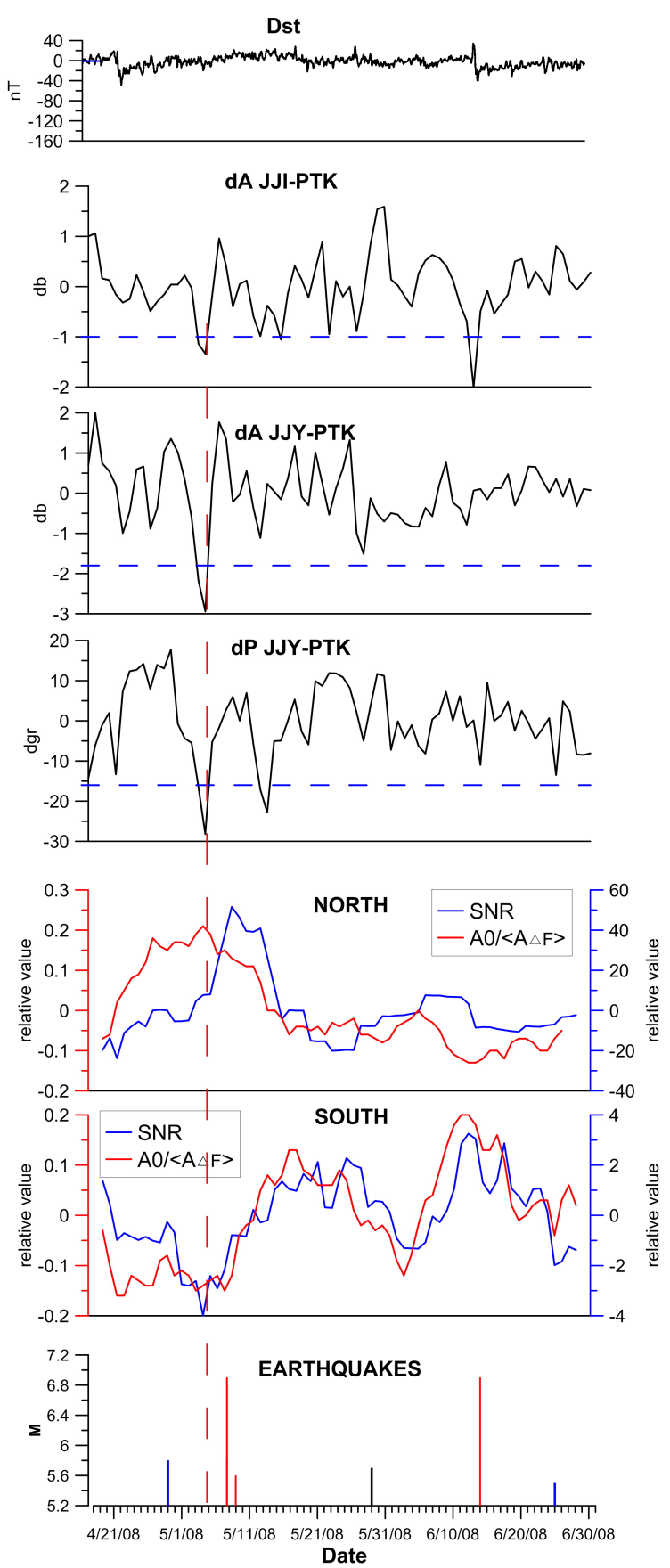

Fig. 5. Ground and satellite observations for the period 18 April-30 June 2008.

The top panel - Dst index of magnetic activity. Three next panels - residual amplitude of JJI $(22.2 \mathrm{kHz})$ signal and residual amplitude and phase of JJY $(40 \mathrm{kHz})$ signal registered in PetropavlovskKamchatsky; two next panels - deviation of real data from model for North and South areas for satellite observation. The bottom panel - magnitude of EQs starting from $M=5$. Black line here indicates EQ with epicenter outside sensitivity zones for ground receptions; blue lines show EQs with epicenters outside the reception zone for satellite. Red lines correspond to common EQ. Dotted lines in 3 top panels show the level of 2 standard deviations $(2 \sigma)$.
For the 13 June earthquake anomalies are detected only in JJI signal. A decrease of the amplitude of the signal is observed 2-3 days before the earthquake, and it is more significant that in the previous case.

It should be noted that during the all period of analysis (April-June 2008) no signal anomalies in the control radio paths have been observed and there was a rather weak magnetic activity.

For satellite observation in an area above the seismic active region (North) an enhancement of both characteristics is revealed before and after 7 May earthquake. An increase of SNR starts 3 days before earthquake, reaches maximum next day after earthquake and continues 3 days after it. ISB shows a maximum 3 days before earthquake and its increase begins about a week before. In the magnetically conjugate area (South) the situation is quite opposite. Depletion in both characteristics is observed in the period of their enhancement in the North area. Anomalies in satellite data coincide in time with those in the ground-based observation. The mechanism of observed effects, able to produce the opposite behavior of SNR in South and North, cannot be defined. At this purpose, more data and other information must be collected.

For the earthquake on 13 June no effect is observed in the North area while some decrease can be detected in the South area before the earthquake. This effect can be connected with the earthquake, but it can be caused other reasons. We have no confirmation here from ground observation.

It was found previously from ground observation (Rozhnoi et al., 2007b) that the most evident and long-continued disturbances in VLF/LF signal are observed during the periods of strong seismic activity when several earthquakes take place in some region within the short time interval (some days). In the case in question the earthquake on 7 May was preceded by process of seismic activity increase, but the seismic activity on 13 July started suddenly with the main shock. Different seismic regime of the earthquakes could cause difference in detected VLF/LF signal anomalies. Effect in both signals (JJI and JJY) for ground observations and in JJY signal for satellite observation is found before the first earthquake. For the second earthquake anomalies are observed in JJI signal only.

\section{Discussion and conclusion}

Satellite and ground observations are independence methods of monitoring. Though it is not so obvious that both satellite and ground effects are excited by the same generation mechanism on the ground, such a simultaneous analysis can be more reliable in earthquake precursor study.

We have presented here once more a comparison of ground and satellite results during periods of seismic activity. Ground observations results are more clear and reliable in comparison with satellite data and confirm the previous studies. It was found from statistical analysis (Rozhnoi et al., 
2004) that the anomalies in the VLF/LF signal are observed for earthquakes with $M \geq 5.5$ and the most probable period of anomalies appearance is 2-7 days before an earthquake and 6-7 days after it. The VLF/LF radio signal method is considered to be a reliable and an efficient tool for the revelation of precursory activity on the occasion of strong earthquakes, especially in multi-stations observations. A network of station provides an opportunity to analyse signals from the same transmitters in the crossing wave paths and detect the area of the oncoming earthquake. Such observations recently have been made in three European VLF/LF stations - Moscow, Bari and Graz - for the earthquake in L'Aquila (Italy) 6 April 2009 (Rozhnoi et al., 2009).

As regards the satellite observations, we have found an apparent effect, but its behaviour differs from the results of previous works (Rozhnoi et al., 2007a; Muto et al., 2008). Satellite observations are not so easy to analyze and interpret. In the ground reception the position of transmitters and receivers are fixed and registration is uninterrupted at the same region. While, in satellite observation when applied to the situation above a fixed point on the ground there are three problems: (1) too large longitudinal distances between adjacent orbits (about $2500 \mathrm{~km}$ in a case of DEMETER orbits at the middle latitudes); (2) one day time intervals between orbits above the point in the same local time; and (3) variation of satellite measurements not only as a function of time but also as function of longitude and latitude due to both the satellite motion on its orbit and to the regular drift of the orbit position. In the present work an additional complication in satellite LF signal analysis arises from rough spectral resolution $(3.255 \mathrm{kHz})$ in the high frequency range and limited reception zone on account of the low transmitter power.

The method of correlated analysis of satellite and ground VLF signal observations is a new technique. The work in this area started only a few years ago when DEMETER space observations provided a very interesting opportunity to investigate earthquakes electromagnetic precursors in VLF/LF range from ground transmitters. More data must be collected and further analyses must be performed for better understanding of the mechanism of observed effects.

Edited by: M. E. Contadakis

Reviewed by: two anonymous referees

\section{References}

Berthelier, J. J., Godefroy, M., Leblanc, F., et al.: ICE, the electric field experiment on DEMETER, Planet. Space Sci., 54(5), 456471, 2006.

Biagi, P. F., Piccolo, R., Castellana, L., Maggipinto, T., Ermini, A., Martellucci, S., Bellecci, C., Perna, G., Capozzi, V., Molchanov, O. A., Hayakawa, M., and Ohta, K.: VLF-LF radio signals collected at Bari (South Italy): a preliminary analysis on signal anomalies associated with earthquakes, Nat. Hazards Earth Syst.
Sci., 4, 685-689, 2004,

http://www.nat-hazards-earth-syst-sci.net/4/685/2004/.

Biagi, P. F., Castellana, L., Maggipinto, T., Maggipinto, G., Minafra, A., Ermini, A., Capozzi, V., Perna, G., Solovieva, M., Rozhnoi, A., Molchanov, O. A., and Hayakawa, M.: Decrease in the electric intensity of VLF/LF radio signals and possible connections, Nat. Hazards Earth Syst. Sci., 7, 423-430, 2007, http://www.nat-hazards-earth-syst-sci.net/7/423/2007/.

Biagi, P. F., Castellana, L., Maggipinto, T., Loiacono, D., Augelli, V., Schiavulli, L., Ermini, A., Capozzi, V., Solovieva, M. S., Rozhnoi, A. A., Molchanov, O. A., and Hayakawa, M.: Disturbances in a VLF radio signal prior the $M=4.7$ offshore Anzio (central Italy) earthquake on 22 August 2005, Nat. Hazards Earth Syst. Sci., 8, 1041-1048, 2008,

http://www.nat-hazards-earth-syst-sci.net/8/1041/2008/.

Boudjada, M. Y., Schwingenschuh, K., Biernat, H. K., Berthelier, J. J., Blecki, J., Parrot, M., Stachel, M., Aydogar, Ö., Stangl, G., and Weingrill, J.: Similar behaviors of natural ELF/VLF ionospheric emissions and transmitter signals over seismic Adriatic regions, Nat. Hazards Earth Syst. Sci., 8, 1229-1236, 2008, http://www.nat-hazards-earth-syst-sci.net/8/1229/2008/.

Hayakawa, M., Molchanov, O. A., Ondoh, T., and Kawai, E.: The precursory signature effect of the Kobe earthquake on VLF subionospheric signals, J. Comm. Res. Lab., Tokyo, 43, 169180, 1996.

Hayakawa, M., Ohta, K., Maekawa, S., Yamauchi, T., Ida, Y., Gotoh, T., Yonaiguchi, N., Sasaki H., and Nakamura, T.: Electromagnetic precursors to the 2004 Mid Niigata Prefecture earthquake, Phys. Chem. Earth, 31, 356-364, 2006.

Horie, T., Yamauchi, T., Yoshida, M., and Hayakawa M.: The wavelike structures of ionospheric perturbation associated with Sumatra earthquake of 26 December 2004, as revealed from VLF observation in Japan of NWC signals, J. Atmos. Sol.-Terr. Phy., 69, 1021-1028, 2007.

Molchanov, O., Rozhnoi, A., Solovieva, M., Akentieva, O., Berthelier, J. J., Parrot, M., Lefeuvre, F., Biagi, P. F., Castellana, L., and Hayakawa, M.: Global diagnostics of the ionospheric perturbations related to the seismic activity using the VLF radio signals collected on the DEMETER satellite, Nat. Hazards Earth Syst. Sci., 6, 745-753, 2006, http://www.nat-hazards-earth-syst-sci.net/6/745/2006/.

Muto, F., Yoshida, M., Horie, T., Hayakawa, M., Parrot, M., and Molchanov, O. A.: Detection of ionospheric perturbations associated with Japanese earthquakes on the basis of reception of LF transmitter signals on the satellite DEMETER, Nat. Hazards Earth Syst. Sci., 8, 135-141, 2008, http://www.nat-hazards-earth-syst-sci.net/8/135/2008/.

Muto, F., Horie, T., Yoshida, M., Hayakawa, M., Rozhnoi, A., Solovieva, M., and Molchanov, O. A.: Ionospheric perturbations related to the Miyagi-oki earthquake on $16 \mathrm{Au}$ gust 2005, as seen from Japanese VLF/LF subionospheric propagation network, Phys. Chem. Earth, 34(6-7), 449-455, doi:10.1016/j.pce.2008.09.010, 2009.

Rozhnoi, A., Solovieva, M. S., Molchanov, O. A., and Hayakawa, M.: Middle latitude LF $(40 \mathrm{kHz})$ phase variations associated with earthquakes for quiet and disturbed geomagnetic conditions, Phys. Chem. Earth, 29, 589-598, 2004.

Rozhnoi, A. A., Solovieva, M. S., Molchanov, O. A., Hayakawa, M., Maekawa, S., and Biagi, P. F.: Anomalies of LF signal dur- 
ing seismic activity in November-December 2004, Nat. Hazards Earth Syst. Sci., 5, 657-660, 2005,

http://www.nat-hazards-earth-syst-sci.net/5/657/2005/.

Rozhnoi, A., Molchanov, O., Solovieva, M., Gladyshev, V., Akentieva, O., Berthelier, J. J., Parrot, M., Lefeuvre, F., Hayakawa, M., Castellana, L., and Biagi, P. F.: Possible seismo-ionosphere perturbations revealed by VLF signals collected on ground and on a satellite, Nat. Hazards Earth Syst. Sci., 7, 617-624, 2007a, http://www.nat-hazards-earth-syst-sci.net/7/617/2007/.

Rozhnoi, A., Solovieva, M., Molchanov, O., Biagi, P.-F., and Hayakawa, M.: Observation evidences of atmospheric Gravity Waves induced by seismic activity from analysis of subionospheric LF signal spectra, Nat. Hazards Earth Syst. Sci., 7, 625$628,2007 b$,

http://www.nat-hazards-earth-syst-sci.net/7/625/2007/.

Rozhnoi, A., Solovieva, M., Molchanov, O., Akentieva, O., Berthelier, J. J., Parrot, M., Biagi, P. F., and Hayakawa, M.: Statistical correlation of spectral broadening in VLF transmitter signal and low-frequency ionospheric turbulence from observation on DEMETER satellite, Nat. Hazards Earth Syst. Sci., 8, 11051111, 2008,

http://www.nat-hazards-earth-syst-sci.net/8/1105/2008/.
Rozhnoi, A., Solovieva, M., Molchanov, O., Schwingenschuh, K., Boudjada, M., Biagi, P. F., Maggipinto, T., Castellana, L., Ermini, A., and Hayakawa, M.: Anomalies in VLF radio signals prior the Abruzzo earthquake $(M=6.3)$ on 6 April 2009, Nat. Hazards Earth Syst. Sci., 9, 1727-1732, 2009,

http://www.nat-hazards-earth-syst-sci.net/9/1727/2009/.

Slominska, E., Blecki, J., Parrot, M., and Slominski, J.: Satellite study of VLF ground-based transmitter signals during seismic activity in Honshu Island, Phys. Chem. Earth Pts. A/B/C, 34(67), 464-473, 2009.

Solovieva, M. S., Rozhnoi, A. A., and Molchanov, O. A.: Variations in the parameters of VLF signals on the DEMETER satellite during the periods of seismic activity, Geomagn. Aeronomy+, 49(4), 532-541, 2009. 